\title{
The Multiple Ideologies of Shaping Cambodian Students' Chinese Language Learning Experiences
}

\author{
Jia Li ${ }^{1}$, Juan Dong ${ }^{1} \&$ Xia Li $^{2}$ \\ ${ }^{1}$ School of Foreign Languages, Yunnan University, Kunming, China \\ ${ }^{2}$ Financial Affairs Institution, Yunnan University, Kunming, China \\ Correspondence: Juan Dong, School of Foreign Languages, Yunnan University, Kunming, China.
}

Received: September 10, 2019 Accepted: October 1, 2019 Online Published: October 3, 2019

doi: 10.5539/elt.v12n11p1

URL: https://doi.org/10.5539/elt.v12n11p1

\begin{abstract}
In light of the increasing prominence of China's Belt and Road (B\&R) Initiatives and China's soft power projection to its neighboring countries, China's relations with Southeast Asian countries are getting closer. In recent years, a large number of Cambodian students have come to China for higher education. Informed by the theories of linguistic capital and language ideology, the present study aims to study the the macro-social factors mediated in the Cambodian students' Chinese language learning experiences. For current study, the data was collected from Guizhou Minzu University and Qiannan Normal University for Nationalities through semi-structured interview, questionnaire, online interactions, and the collection of linguistic autobiographies as well as other relevant documents and materials. The findings of the study show that there are four main factors influencing Cambodian students' higher education in China: (i) political factors: national and governmental policies; (ii) cultural factors: historical influences; (iii) educational factors: influences of schools and communities, parental strategies; (iv) economic factors: employment prospects and tourism. Based on the findings mentioned above, the study suggests that given the rapid increasing number of Cambodian international students in China, it is imperative for Chinese government and universities to consider how to better meet Cambodian international students' study needs and employment prospects.
\end{abstract}

Keywords: Cambodian students, multiple ideologies, language learning experiences, Chinese Universities, influencing factors

\section{Introduction}

Cambodia is a traditional friendly country of China and one of the essential countries along the B\&R road. The promotion of B\&R initiative can combine China's rapid economic development with the national interests of Cambodia, especially in the field of education (Wang, 2015). Currently, Cambodian international students study in China mainly through the following ways: Chinese government scholarship program; Confucius institute scholarship program; School-enterprise, school-business and school-school cooperation; self-funded study abroad and so on. According to the figure shown in the year 2016, the Chinese government scholarship program had accepted more than 2,000 Cambodian international students in different Chinese universities (Liu, 2017).

In recent decades, many scholars have conducted various studies on Cambodian culture, history, economy, education, government policy and other fields (Jacobsen, 2013; Carpenter, 2011; Slocomb, 2010; Corfield, 2009; Collins, 2009; Saroeun, 2017; Dy, 2004; Mohd Shariff, 2010). In these years, with the promotion of China's B\&R initiative, an increasing number of Chinese scholars have focused on Cambodian language education. More specifically, some examined the challenge and opportunities of learning Chinese language and cultivating Chinese speaking guides, targeting on strategies of improving Cambodian people's Chinese language proficiency (Xu, 2018; Liu, 2017). Guan and Peng (2011) investigated the English varieties in Cambodia, stating that English is one of the official languages which play a significant role in the communication and development in the fields of politics, economy and culture. Further, Yang (2016) asserted that Cambodian higher education governance has witnessed four different governance models: Model of French Colonial Administration, Model under Khmer Rouge, Model within Vietnam Occupation, and Open Model since 1990s, thus indicating its development trace from the unique model of colonization to the hybrid model of post colonialism. However, it can be concluded that studies concentrated on Cambodian international students are very scarce. 
Under the background of China's B\&R, there is a boom of learning Chinese in countries along the route. Objectively, the reasons why China is welcomed by Cambodian students are as follows. First, China has low requirements on the Chinese language proficiency for international students. Second, Chinese government provides many types of scholarships for international students. Third, students' employment prospects are pleasant after they graduated from Chinese universities. However, these factors do not fully explain why Cambodian students receive higher education in China. Therefore, this study believes that in-depth understanding of the main influencing factors of Cambodian students receiving higher education in China is conducive for Chinese government and universities to carry out relevant teaching policies and teaching plans to understand and meet the demand of Cambodian international students' study and employment.

\section{Linguistic Capital and Language Ideology}

In terms of linguistic capital, Bourdieu (1991) states that "different speakers possess different quantities of 'linguistic capital' - that is, the capacity to produce expressions a propos, for a particular market. Moreover, the distribution of linguistic capital is related in specific ways to the distribution of other forms of capital (economic capital, cultural capital, etc.) which define the location of an individual within the social space." (p. 18). In linguistic capital discourse, Silver (2005) also examined the policy of English language education in Singapore and how government officials and educators make English playing a role in the development of modern economy. Meanwhile, Park (2011), Smits (2003) respectively discussed the role of English in Korean job market, Turkish Kurdish and Arab women regard language as a socio-economic resource. These studies show that certain languages are valued more highly than others in a given language market, such as English. In reality, a speaker's English proficiency, to some extent, determines whether a person can get a valuable, well-paid job in the market. Obviously, a person with more linguistic capital will have more advantages in employment and thus gain more benefits. Thus, this study takes linguistic capital as the theoretical basis, combining the actual situation of Cambodian international students to deeply analyze the factors influencing their decisions of studying in China.

Furthermore, Curdt-Christiansen (2009) defined language ideology as something related to and intertwined with economic, political, socio-cultural, linguistic factors and parents' educational experience and expectations. Many researchers, such as King (2000), clarified the definition of 'language ideology' from different perspectives. For instance, Park (2017) studied the experiences of four married immigrant women from Southeast Asia in rural Korea, aiming to reveal how immigrant women cope with the challenges and difficulties in their communication with native Korean people under the background of dominated Korean social power. Surprisingly, they choose to use different pronunciation of Korean language to identify themselves and integrated into Korean society. Simultaneously, Dong (2009) published a paper named "language ideology and migrant workers' identity construction in a public primary school in Beijing". Curdt-christiansen (2016) also investigated "the conflict between language ideology and language practice in multilingual families in Singapore". In short, these studies indicate that the language ideology of students themselves and their parents', in a sense, will influence them to make essential choice of life, particularly in education. Concerning to Cambodia, most Cambodian students and parents regard language as a capital because of the increasing economic cooperation between China and Cambodia. Therefore, their language ideology is of great importance in their educational choice.

\section{Methodology}

\subsection{Participants}

The participants of this study are totally 18 people, mainly Cambodian students from Guizhou Minzu University and Qiannan Normal Universty for Nationalities and their mother tongue is Khmer. Among them, six are from Phnom Penh, Cambodia's capital; 4 people from Takeo province; 2 from Prey Veng province, others from Siem Reap province, Kiri province, Kampong province and kampong Cham. Among the 14 students in Guizhou Minzu University, 4 are female students. Surprisingly, there is only one female student in Qiannan Normal University for Nationalities. They all study in different grades (from the first year of undergraduate to the third year of postgraduate) with different majors. The average age of the participants is 23 years old (range: 20-30) and the average time they lived in China was 1.6 years (range: $0-5$ years). At the beginning of this study, 5 of them had just arrived in China and had no Chinese learning experiences, 4 of them have been studying in China for one year, 7 students have been studying in China for two and a half years; 2 have been studying in China for more than three years. In addition, one has passed HSK level 6, four of them have passed HSK level 4, five passed HSK level 3, four passed HSK level 2. The rest of the students are at the beginning stage of learning Chinese. To understand why they decided to come to China for higher education and what are the social factors that influence their migration trajectories, the study is going to explore two research questions as below:

(1) What are the social factors that influence Cambodian students coming to China for higher education? 
(2) What are the meanings of learning Chinese for Cambodian students?

Table 1. Participant's profile

\begin{tabular}{|c|c|c|c|c|c|}
\hline Participants & $\begin{array}{l}\text { Gender } \\
\mathrm{M} / \mathrm{F}\end{array}$ & Nationality & $\begin{array}{l}\text { Chinese } \\
\text { Proficiency }\end{array}$ & $\begin{array}{l}\text { Time in } \\
\text { China } \\
\text { (Year) }\end{array}$ & $\begin{array}{l}\text { Major } \\
\text { Undergraduate (U) } \\
\text { Postgraduate (P) }\end{array}$ \\
\hline N1 & M & Cambodia & HSK 4 & 3 & $\begin{array}{l}\text { Industrial And commercial } \\
\text { management }(\mathrm{U})\end{array}$ \\
\hline N2 & M & Cambodia & HSK 4 & 3 & $\begin{array}{l}\text { Industrial and commercial } \\
\text { management }(\mathrm{U})\end{array}$ \\
\hline N3 & M & Cambodia & HSK6 & 4 & comparative literature $(\mathrm{P})$ \\
\hline N4 & M & Cambodia & HSK3 & 3 & $\begin{array}{l}\text { Industrial and commercial } \\
\text { management }(\mathrm{U})\end{array}$ \\
\hline N5 & M & Cambodia & HSK3 & 3 & $\begin{array}{l}\text { Industrial and commercial } \\
\text { management }(\mathrm{U})\end{array}$ \\
\hline N6 & M & Cambodia & HSK3 & 2.5 & Chinese language (U) \\
\hline N7 & M & Cambodia & No & $<1$ & Chinese language (U) \\
\hline N8 & M & Cambodia & No & $<1$ & $\begin{array}{l}\text { Industrial and commercial } \\
\text { management }(\mathrm{U})\end{array}$ \\
\hline N9 & M & Cambodia & HSK3 & 2.5 & Economics (U) \\
\hline N10 & M & Cambodia & HSK4 & 3 & Economics (U) \\
\hline N11 & $\mathrm{F}$ & Cambodia & HSK3 & 2.5 & Economics (U) \\
\hline N12 & $\mathrm{F}$ & Cambodia & HSK4 & 5 & Art Design (U) \\
\hline N13 & $\mathrm{F}$ & Cambodia & HSK2 & $<1$ & Chinese literature $(\mathrm{P})$ \\
\hline N14 & $\mathrm{F}$ & Cambodia & HSK2 & 2.5 & Chinese literature (U) \\
\hline N15 & $\mathrm{F}$ & Cambodia & HSK2 & 2.5 & Economics (U) \\
\hline N16 & M & Cambodia & HSK2 & 2.5 & $\begin{array}{l}\text { Industrial and commercial } \\
\text { management }(\mathrm{U})\end{array}$ \\
\hline N17 & $\mathrm{M}$ & Cambodia & No & 2.5 & Economics (U) \\
\hline N18 & M & Cambodia & No & $<1$ & Chinese language (U) \\
\hline
\end{tabular}

\subsection{Data Collection and Analysis}

For current study, the data was collected from Guizhou Minzu University and Qiannan Normal University for Nationalities through semi-structured interview, questionnaire, online interaction with the auxiliary tools of telephone and WeChat, and the collection of linguistic autobiographies as well as other relevant documents and materials. At the beginning of data collection, basic information of research participants, such as hobbies, families and majors, was acquired mainly through WeChat communication. The researchers then designed questionnaire about their decision of coming to China, for example: "why do you choose China for your higher education? What are your expectations after studying in China?" etc. Later, after analyzing their questionnaire answers and WeChat feedback, further information was obtained through telephone interview according to the information and answers provided by them. In the data collection, considering that their Chinese and English proficiency are different, in order to collect information more conveniently, all participants can answer questions and communicate in Chinese or English. In the whole process, WeChat played a great role after each interview, so that data can be timely fed back at different times (Maeder-qian, 2017). Additionally, the researcher also adopted semi-structured interview for obtaining the in-depth information. Moreover, for getting more comprehensive information, researcher and participants communicated at least twice a week. 


\section{Findings}

According to the research findings, the main influencing factors for Cambodian students to receive higher education in China are as follows: (i) political factors (national and governmental policies); (ii) cultural factors (historical influences); (iii) educational factors (influences of schools and communities, parental strategies); (iv) economic factors (employment prospects and tourism). Figure 1 shows these influencing factors and their proportions respectively.



Figure 1. The proportion of influencing factors

Based on the theories of linguistic capital and language ideology, the data of this study shows that the influencing factors of Cambodian students studying in China are mainly reflected in politics, culture, education and economy. These influencing factors will be respectively introduced in the following text.

\subsection{Political Factors}

Chinese government policy has exerted crucial impact on Cambodian students' higher education in China. On December $22^{\text {nd }}$ in 2009, Chinese vice President Xi Jinping and Cambodian deputy prime minister Sok An jointly hosted the opening ceremony of the Confucius institute at the Cambodian Royal Institute of Jiujiang University. Further, Confucius institutes and Chinese schools have also provided favorable references for the development of Chinese language education in Cambodia (Yu, 2017).

Today, China-Cambodia pragmatic cooperation under the B\&R initiative is to build a community of shared interests, shared future and shared responsibilities, featuring political mutual trust, economic integration and cultural tolerance (Liu, 2017). At the same time, both governments support Cambodian students to receive higher education in China and hope to have more cooperation in the field of education.

Therefore, with the help and support of the Chinese and Cambodian governmental policies, Cambodian students are willing to come to China for higher education in the hope of finding a good job and enjoying China's long history and splendid culture. In this case, it promotes cultural exchanges and friendship between the two countries.

In this study, three Cambodian students said that the Chinese government scholarship, as one of China's educational policies for Cambodian international students, is an important impetus to support Cambodian students to study in China. Influenced by family economic factors, participants N3, N11 and N14 (specifically see Table 3) family income cannot fully support their study and life in China, so the government scholarship, to a great extent, help them to reduce the economic pressure so that they can have more time and energy to concentrate on their studies and ensure the quality of their life.

\subsection{Cultural Factors}

In addition to the influence of national and governmental policies, historical factors are also a major factor affecting Cambodian students studying in China. As is known, China has a long history and splendid civilization of more than 5,000 years. Historically, in Funan time, Cambodia had already paid a visit to China. Liu and Zhou (2017) shows that in the first year of the Yuan dynasty of the eastern Han dynasty, king Funan sent envoys to China and exchanged precious gifts, which was called the earliest contact between the two countries. What's more, Chinese immigrants can be traced back to the southern and northern dynasties of Cambodia. During the late Ming and early Qing dynasties, there was a wave of large-scale Chinese immigrants to Cambodia. Two Cambodian students who took part in the interview also stated they were influenced by their families to study Chinese language. 
(1)N1: My grandparents are Chinese people. So my parents hope that I learn Chinese language for inheriting family traditions.

(2)N12: My grandfather is Cantonese, he taught me Chinese language when I was a kid. So that is why I can speak Chinese language (For example: I can understand the deep meaning of Chinese character) and want to have a further study in China.)

As indicated above, both Liu and Lin shared their families are inextricably linked with Chinese blood. Influenced by their elders, they have a strong interest in China's extensive and profound culture, which promotes their desire to study Chinese language in a further step.

Dai and Liu (2015) pointed out that 'overseas Chinese in Cambodia' not only refer to their Cambodian national political identity, but also reflects their high degree of acceptance of their Chinese identity, especially for the young generations of 'overseas Chinese in Cambodia'. It indicates that 'overseas Chinese in Cambodian' recognize the value of Cambodian culture and Chinese culture. Four participants stated that they came to China to study because they thought China was a great country and they were very interested in Chinese long history and splendid culture.

\subsection{Educational Factors}

Besides the political and cultural factors, the influences of schools and communities are also vital factors which affect Cambodian students to study in China. Perhaps the most essential factors are parental strategies which account for 33\% among all of these factors. Two of the participants said they were influenced by teachers and the communities they lived in.

(1)N3: My university professor told me that doing studies in China is very great. After considering his suggestion, I decide to further my master degree in China.

(2)N10: When my mother chatted with her friends, they told her that if your children study in China, they will find a very good job in the future. And there are many examples in our community. Then, my mother and aunt decided to send me to China for furthering my undergraduate education.

From these two cases, it can be concluded that Cambodian students coming to China for higher education was influenced by schools and communities. In terms of the influence of schools, teachers in Cambodian colleges and universities have a good international awareness because they know that Cambodia needs a large number of Chinese talents and the employment prospect of studying in China is bright. Therefore, in the teaching process, this global awareness will affect students and promote their visions of studying in China. At the same time, the impact of community is also very significant. It is universally admitted that living environment can have a profound impact on individuals in the society. In this situation, the group values of N10's mother's community largely influenced her thinking about her children's study choice and job prospects.

Beyond the influence of schools and communities, parents' decisions are bound to primarily affect their children's education. As can be clearly seen from Table 2 , among the 18 students, 6 international students described that their parents sent them to China for study after they graduated from high school.

Table 2. Participants' reasons for coming to China

\begin{tabular}{|c|c|}
\hline Participants & Reasons for Coming to China \\
\hline N1 & Grandparents are Chinese people \\
\hline $\mathrm{N} 2$ & Chinese culture is very interesting \\
\hline N3 & $\begin{array}{l}\text { Recommendation from a college teacher; Low requirements for study in China; Low } \\
\text { consumption in China; Government scholarship }\end{array}$ \\
\hline N4 & $\begin{array}{l}\text { many Chinese enterprises and companies in Cambodia; Learning Chinese is good for starting } \\
\text { own company }\end{array}$ \\
\hline N5 & Parents' decision \\
\hline N6 & I like China. \\
\hline N7 & Parents' decision \\
\hline N8 & Parents' decision \\
\hline N9 & Parents' decision \\
\hline
\end{tabular}




\begin{tabular}{ll}
\hline N10 & $\begin{array}{l}\text { Influenced by the community, my mother heard that studying in China is } \\
\text { conducive to future employment } \\
\text { N11 }\end{array}$ \\
L12 & $\begin{array}{l}\text { Low consumption; Scholarship } \\
\text { Cantonese. } \\
\text { many Chinese enterprises and companies in Cambodia; Chinese is good for my future } \\
\text { N13 }\end{array}$ \\
N14 & Parents' decision \\
N15 & Parents' decision \\
N16 & China is great \\
N17 & China is much better than other countries \\
N18 & China is great \\
\hline
\end{tabular}

Furthermore, parents of different educational backgrounds and occupations also have a great influence on their children's education. According to the interview with Cambodian students, Figure 2 shows that $50 \%$ of Cambodian parents graduated from high school, $28 \%$ from middle school and $22 \%$ from university.

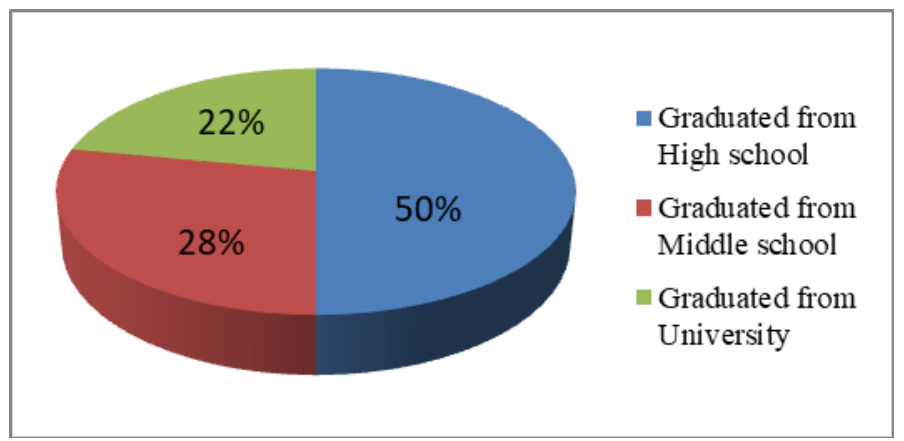

Figure 2. Parents' educational backgrounds

Moreover, as shown in Figure 3, the parents of Cambodian students are mostly businessmen. Second, there are equal Numbers of parents who are farmers and teachers, and very few parents are police, bank clerk and doctors.

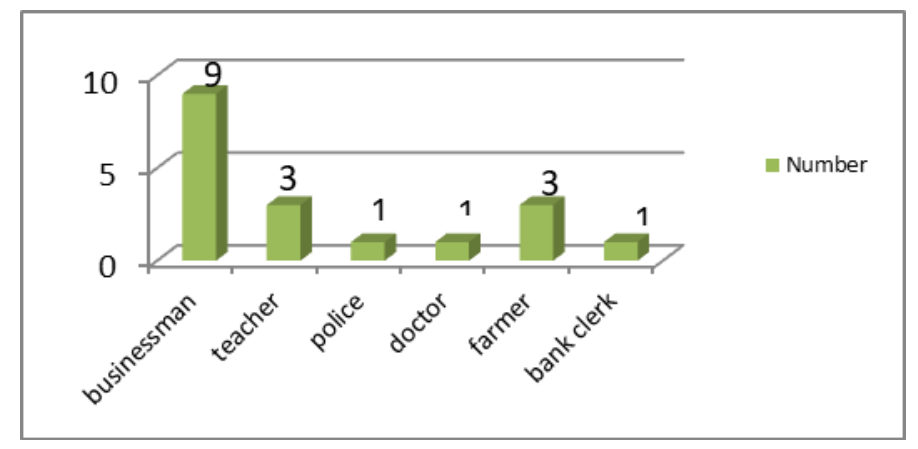

Figure 3. Parents' occupation

It can be concluded that Parents' educational background and occupation affected their ideologies and world values. Meanwhile, parents' ideology and consciousness, to a certain extent, will affect their children's educational decisions. Combined with the educational background of Figure 2 and interviews from some participants, the researcher found that the parents who graduated from the university and high school were strongly willing to send their children to study abroad, because they have a better international vision than those who graduated from 
middle school. Additionally, according to the semi-structured interview, most participants made it clear that their parents hope that they can return home to inherit their family business after graduation from Chinese universities. From Figure 3, we can see that $50 \%$ of parents are businessmen because they see the advantages and profits of studying in China. For example, the bilateral trade cooperation makes Cambodia businessman saw the foreign trade prospects, hoping to meet their business expectations from younger generations.

\subsection{Economical Factors}

Related to political, cultural and educational influences, economy has served an influential factor for Cambodian students to receive higher education in China. Especially in terms of employment prospects and tourism, Cambodia is an ancient country with a long history and civilization in Southeast Asian countries. It is rich in tourism resources and attracts tourists from all over the world with its unique and rich Khmer culture and the world heritage of Angkor Wat, which is known as one of the "seven wonders of the world" the lack of Chinese-speaking tour guides has become a major bottleneck in Cambodia's tourism development. The problems of tour guides mainly focus on Chinese language expressions, and the proportion of tourists dissatisfied with their Chinese proficiency is as high as $69 \%$ (Xu, 2018). Language emerges as a commodity and a resource to recreate new and symbolic values of products and services. Therefore, it can be seen that Cambodian students studying Chinese in China will be of great help to their future employment. For example, participant N13 described:

Researcher: Why do you choose to further your postgraduate study in China?

N13: Actually, I have graduated from university for many years. I have been working in Cambodia for 6 years after graduation. But I think it is not easy to make money and I want to have a brighter future. Nowadays, there are more and more Chinese companies and investment in Cambodia, so I need to learn Chinese language in China, and my Chinese language will improve a lot. I also learn some knowledge of business. I believe I will open my own companies in Cambodia. My dream will come true soon.

From this statement, it can be seen that studying in China, especially learning Chinese language, was found to be of great help to one's economy and employment.

In short, Cambodian students speak English, Chinese and Khmer. They use English to help them to learn Chinese and other languages. By learning Chinese and relying on the Chinese government's B\&R policy, they will have better job prospects. For example, owing to the boom of Cambodian tourism industry and Chinese enterprises, the policies of the two governments provide many opportunities for Cambodian international students studying abroad. Meanwhile, the impact of school and community also play an important role in the educational decisions of Cambodian parents and students.

\section{Implication and Conclusion}

To sum up, this study mainly took 18 Cambodian international students as research participants. Based on theories of linguistic capital and language ideology, the study analyzes the social factors mediated in the Cambodian students' Chinese language learning process structured in politics, culture, education and economy.

The research results show that Chinese and Cambodian national and governmental policies, parental strategies, historical influences, school and community influences, employment prospects and tourism have had an impact on Cambodian students studying in China. Among them, parental strategies, historical factors and employment prospects are the primary influencing factors for Cambodian international students to come to China. At the same time, Parents' occupation and educational backgrounds influence their views on educational opportunities, which are clearly reflected in their interactions with existing educational frameworks and government mandates (Curdt-Christiansen, 2009). Additionally, impacts of school and community, and national and governmental policies are the secondary factors affecting their study in China. As an important trade and cultural exchange center of China, the study on the influencing factors for Cambodian students to receive higher education in China is conducive to the formulation of relevant language policies and plans for Cambodian international students, so as to provide real data and feasible plans for them to study in China. It is hoped that this paper can provide useful references for the cooperation and development in the fields of education, economy and culture between the two countries.

At the same time, this study still has some shortcomings. On the one hand, the number of participants is small, and subsequent studies can further enrich and expand the number of participants, which is conducive to improving the credibility of the research results. On the other hand, this study only analyzes the influencing factors of Cambodian international students studying in China from the perspective of linguistic capital and language ideology. Future studies can take language resources and other perspectives for further research. 


\section{Acknowledgements}

This work was supported by Yunnan University under the Grant [No.18YNUGSP015] and [No. 18YNUGSP051] and funded by the College of Foreign Languages of Yunnan University under the Grant [C176210301].

\section{References}

Bourdieu, P. (1991). Language and symbolic power (p. 18). Harvard University Press.

Carpenter, K. (2011). Slocomb, Margaret, 2010. An Economic History of Cambodia in the Twentieth Century, Singapore. Asian Journal of Social Science, 39(5), 711-712. https://doi.org/10.1163/156853111X614990

Collins, J. M. (2008). Reconstructing access in the Cambodian education system. Inequality in Education (pp. 190-214). Springer, Dordrecht. https://doi.org/10.1007/978-90-481-2652-1_8

Corfield, J. (2009). The history of Cambodia. ABC-CLIO.

Curdt-Christiansen, X. L. (2009). Invisible and visible language planning: Ideological factors in the family language policy of Chinese immigrant families in Quebec. Language Policy, 8(4), 351-375. https://doi.org/10.1007/s10993-009-9146-7

Curdt-Christiansen, X. L. (2016). Conflicting language ideologies and contradictory language practices in Singaporean multilingual families. Journal of Multilingual and Multicultural Development, 37(7), 694-709. https://doi.org/10.1080/01434632.2015.1127926

Dai F., \& Liu F, (2015). The identification of Cambodian Chinese and their perceptions on China. Overseas Chinese Journal of Bagui, 4, 3-10.

Dong, J. (2009). Isn't it enough to be a Chinese speaker: Language ideology and migrant identity construction in a public primary school in Beijing. Language \& Communication, 29(2), 115-126. https://doi.org/10.1016/j.langcom.2009.01.002

Dy, S. S. (2004). Strategies and Policies for Basic Education in Cambodia: Historical Perspectives. International Education Journal, 5(1), 90-97.

Guan R. Z., \& Peng X. Q. (2011). A Study of English Varieties in Ten Asean Countries-Cambodian English. China Academic Journal Publishing House, Around Southeast Asia, 88-91.

Jacobsen, T., \& Stuart-Fox, M. (2013). Power and political culture in Cambodia. Singapore: Asia Research Institute, National University of Singapore.

Liu, X. D., \& Zhou, Z. Y. (2017). Opportunities and challenges of Chinese learning in Cambodia under the background of One Belt And One Road. Journal of Jiujiang University (Social Science Edition), 4, 10-14.

Maeder-Qian, J. (2018). Intercultural experiences and cultural identity reconstruction of multilingual Chinese international students in Germany. Journal of Multilingual and Multicultural Development, 39(7), 576-589. https://doi.org/10.1080/01434632.2017.1410161

Mohd Shariff, M. N., Peou, C., \& Ali, J. (2010). Moderating effect of government policy on entrepreneurship and growth performance of small-medium enterprises in Cambodia. International Journal of Business and Management Science, 3(1), 57.

Park, J. S. Y. (2011). The promise of English: Linguistic capital and the neoliberal worker in the South Korean job market. International Journal of Bilingual Education and Bilingualism, 14(4), 443-455. https://doi.org/10.1080/13670050.2011.573067

Park, M. Y. (2017). I want to learn Seoul speech! language ideologies and practices among rural marriage-migrants in South Korea. International Journal of Bilingual Education and Bilingualism, 1-14. https://doi.org/10.1080/13670050.2017.1351419

Saroeun, P. (2017). Causes of Lower Secondary School Dropout in Rural Cambodia: A Cause Study of Stoeung Treng. Royal University of Phnom Penh.

Silver, R. E. (2005). The discourse of linguistic capital: Language and economic policy planning in Singapore. Language Policy, 4(1), 47-66. https://doi.org/10.1007/s10993-004-6564-4

Smits, J., \& Gündüz-Hoşgör, A. (2003). Linguistic capital: Language as a socio-economic resource among Kurdish and Arabic women in Turkey. Ethnic \& Racial Studies, 26(5), 829-853. https://doi.org/10.1080/0141987032000109050

Wang, X. M., \& Yang Y. F. (2015). One Belt And One Road construction and the mission of Confucius institute. 
Journal of Jiujiang University, 4, 15-16.

Xu, Y. J. (2018). Training Strategies for Chinese Speaking Guides in Cambodia in the Context of "One Belt \& One Road". Journal of Sichuan Tourism, 3, 88-91.

Yang, W. M. (2016). Research on the evolution of governance model of higher education in Cambodia. International and Comparative Education, 4, 43-50.

Yu, Q. H., \& Chen, J. W. (2017). Current situation and trend of Chinese education in Cambodia. Journal of Jiujiang University, 4, 23-25.

\section{Copyrights}

Copyright for this article is retained by the author(s), with first publication rights granted to the journal.

This is an open-access article distributed under the terms and conditions of the Creative Commons Attribution license (http://creativecommons.org/licenses/by/4.0/). 